
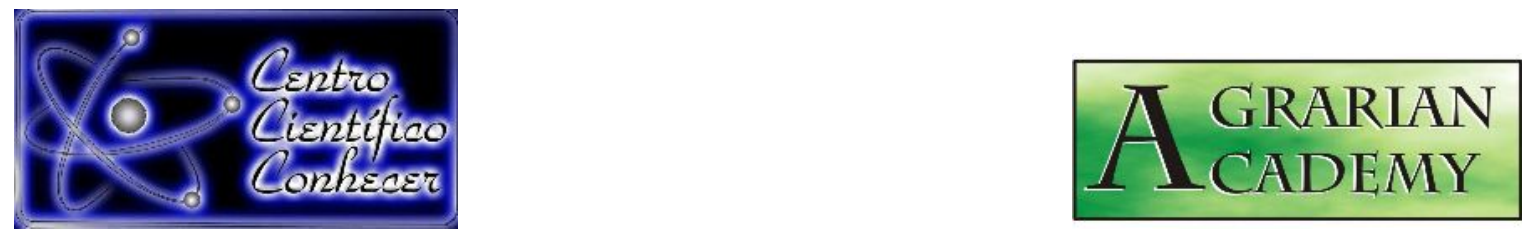

\title{
MELHORAMENTO GENÉTICO E QUALIDADE DE ABELHAS RAINHAS MATRIZES SELECIONADAS PARA PRODUÇÃO DE MEL
}

Renata Valéria Regis de Sousa Gomes ${ }^{1}$; Kátia Peres Gramacho²; Lionel Segui Gonçalves $^{2}$

${ }^{1}$ Departamento de Zootecnia, Universidade Federal Rural de Pernambuco, Recife,

PE, Brasil; (renatav_sousa@hotmail.com)

${ }^{2}$ Departamento de Ciência Animal, Universidade Federal Rural do Semi-árido

Recebido em: 02/06/2019 - Aprovado em: 15/06/2019 - Publicado em: 22/07/2019

DOI: 10.18677/Agrarian_Academy_2019a20

\begin{abstract}
RESUMO
O objetivo desse trabalho foi avaliar as características comportamentais e produtivas de abelhas africanizadas (Apis mellifera L.) para estabelecimento de um programa de seleção de rainhas matrizes. Foram transferidas 30 colônias de abelhas africanizadas (Apis mellifera L.) dos apiários de apicultores colaboradores da região do litoral e zona da mata sul de Pernambuco para o apiário experimental do Departamento de Zootecnia (AEDZ/UFRPE). As colônias foram avaliadas quinzenalmente no período de janeiro de 2014 a fevereiro de 2016 . Na 1a fase experimental foram coletados dados referentes as características comportamento higiênico $(\mathrm{CH})$, postura da rainha $(\mathrm{PR})$, defensividade $(\mathrm{DE})$ e produção de mel $(\mathrm{PM})$. $\mathrm{Na} 2^{\underline{a}}$ fase experimental foram produzidas rainhas de $1^{\underline{a}}, 2^{\underline{a}}$ e $3^{\underline{a}}$ geração filhas das matrizes com média de seleção $\mu S \geq 8,0$ e foi avaliada a produção de mel. Observou se um ganho genético de $0,7 \mathrm{Kg}$ na produção de mel nas colônias com rainhas de $3^{\underline{a}}$ geração, o que representa aumento de $5,4 \%$ na produção de mel em relação as colônias matrizes e 49,2\% comparada a produção nos apiários dos apicultores parceiros. As características comportamentais e produtivas avaliadas e a forma de cálculo para a obtenção da média de seleção foi eficiente para o estabelecimento de um programa de seleção de rainhas matrizes, considerando o comportamento higiênico como a característica mais importante.
\end{abstract}

PALAVRAS-CHAVE: apicultura, Apis mellifera.comportamento higiênico

\section{GENETIC IMPROVEMENT AND QUALITY OF QUEEN BEES MATRIXES SELECTED FOR HONEY PRODUCTION}

\begin{abstract}
The objective of this study was to evaluate the behavioral and productive characteristics of Africanized bees (Apis mellifera L.) to establish a program for the selection of queen queens. Thirty africanized bee (Apis mellifera L.) colonies were
\end{abstract}


transferred from apiaries of partner beekeepers in coastal zone and south zona da mata of Pernambuco to experimental apiary of Department of Animal Science (AEDZ/UFRPE). Colonies were fortnightly evaluated from January 2014 to February 2016. In the first experimental phase data were collected regarding the characteristics hygienic behavior $(\mathrm{CH})$, queen posture $(\mathrm{PR})$, defensiveness $(\mathrm{DE})$ and honey production (PM). For the 2nd experimental phase, queens were produced in 1st, 2nd and 3rd generations of daughters of matrixes with $\mu S \geq 8,0$ and honey production was evaluated. Genetic gain of $0,7 \mathrm{~kg}$ in honey production in colonies with $3^{\text {rd }}$ generation queens was observed, representing a $5,4 \%$ increase in honey production over the matrix colonies and $49,2 \%$ compared to production in apiaries of partner beekeeper. The behavioral and productive characteristics evaluated and the calculation method to obtain the mean of selection were efficient for the establishment of a program of selection of matrices, considering the hygienic behavior as the most important characteristic.

KEYWORDS: hygienic behavior, beekeeping, Apis mellifera.

\section{INTRODUÇÃO}

A abelha é a espécie animal de maior importância agrícola e apresenta na sua colônia uma estrutura interna de sub-famílias devido a poliandria da rainha que aumenta a diversidade genética intracolônia (TARPY et al., 2011). O que resulta na maioria das vezes na falta de homogeneidade na produção das colmeias dos apiários, fazendo-se necessário a substituição das rainhas das colônias menos produtivas por rainhas melhores.

O aumento da produção é um dos objetivos do melhoramento genético de abelhas, sendo essencial a escolha de colônias matrizes para serem doadoras de larvas para produção de rainha utilizando métodos padronizados e confiáveis, que considerem a ação conjunta da qualidade genética das abelhas e das condições ambientais (MARTINEZ; SOARES, 2012).

A qualidade genética da abelha rainha está relacionada com sua expressão fenotípica comportamental, serem livres de doenças e pragas e apresentarem bom desempenho reprodutivo (HATJINA et al., 2014). Sendo a saúde da rainha essencial para o desenvolvimento e sucesso da colônia, considerando que uma rainha saudável e de alta qualidade pode mitigar os efeitos de doenças sobre a aptidão da colônia ou até mesmo tornar as colônias mais resistentes à doença (AMIRI et al., 2017).

O poli-hibrido abelha africanizada, conhecida como abelha brasileira, apresenta alta tolerância a doenças e pragas devido a sua capacidade de detectar e remover crias mortas, doentes ou parasitas do interior ninho, que consiste na característica fenotípica chamada de comportamento higiênico (GRAMACHO; GONÇALVES, 2009). O comportamento higiênico é a característica mais importante das abelhas por retardar ou evitar o desenvolvimento de doenças na colônia, constituindo-se como um importante mecanismo de imunidade das abelhas, conferindo resposta rápida de defesa quando ocorre exposição a algum patógeno ou parasito (WAGONER et al., 2018). Sendo considerada uma excelente ferramenta para seleção de rainhas matrizes, por proporcionar a sanidade das colônias, evitando a utilização de fármacos para o controle de doenças e pragas, e a consequente contaminação dos produtos apícolas (ALVAREZ; SERRANO, 2011).

Entre o conjunto de técnicas para seleção e produção de rainhas, o fornecimento para os apicultores de rainhas virgens com alto nível de 
comportamento higiênico, para acasalamento com os zangões disponíveis na natureza, tem resultado em colônias de alta qualidade genética (BIGIO et al., 2014). Colônias saudáveis apresentam eficiência na coleta dos recursos das flores, o que favorece seu crescimento e desenvolvimento (SPIVAK et al., 2017). Fazendo-se necessário o desenvolvimento e divulgação de métodos que facilite a aplicação prática (CAMARGO et al., 2015).

O objetivo desse trabalho foi avaliar as características comportamentais e produtivas de abelhas africanizadas (Apis mellifera L.) para estabelecimento de um programa de seleção de rainhas matrizes.

\section{MATERIAL E METÓDOS}

A pesquisa foi realizada no Apiário Experimental do Departamento de Zootecnia da Universidade Federal Rural de Pernambuco - AEDZ/UFRPE, após a transferência de 30 colônias de abelhas do polihíbrido africanizada (Apis mellifera L.), com rainhas fecundadas naturalmente, instaladas em colmeias padrão modelo Langstroth numeradas. Todas as famílias de abelhas foram doadas por apicultores colaboradores localizados na região do litoral e zona da mata sul de Pernambuco, que povoam seus apiários com enxames capturados na natureza em caixas iscas.

O AEDZ/UFRPE está situado na microrregião fisiográfica do litoral e zona da mata de Pernambuco, na cidade do Recife-PE-Brasil, com o clima caracterizado por existir apenas duas estações no ano, a chuvosa (inverno) e a seca (verão). O período chuvoso compreende os meses de maio a agosto, com temperatura média de $24^{\circ} \mathrm{C}$ e média pluviométrica de $725 \mathrm{~mm}$. O verão, que são os meses mais quentes, a temperatura média a chega a $27^{\circ} \mathrm{C}$ e média pluviométrica de $515 \mathrm{~mm}$ (APAC, 2015).

O registro dos dados das colmeias foi iniciado em janeiro de 2014 com inspeções quinzenais, finalizando em fevereiro de 2016. A pesquisa constou de duas fases experimentais, onde na $1^{\underline{a}}$ fase foram coletados dados referentes as características comportamento higiênico $(\mathrm{CH})$, postura da rainha $(\mathrm{PR})$, defensividade (DE) e produção de mel (PM).

Foram realizados 9 testes de comportamento higiênico $(\mathrm{CH})$, no período de 26/03/2014 a 27/03/2015, utilizando-se o método de perfuração das células de crias de acordo com a metodologia de Newton e Ostasiewski (1986), modificado e adaptado por Gramacho e Gonçalves (1994). Estabeleceu - se o critério de considerar higiênicas as colônias que o percentual de limpeza $(\mathrm{CH})$ fosse igual ou superior a $80 \%$, intermediárias até $50 \%$ e não higiênica abaixo de $50 \%$.

Nas inspeções quinzenais foram contados os números de quadros com crias, alimento (mel e pólen), cera alveolada, quadro vazio, presença de rainha e realeiras. O comportamento defensivo das abelhas foi avaliado por meio da metodologia de análise subjetiva de campo que qualifica o comportamento das colônias em colônia super mansa, colônia mansa, colônia defensiva e colônia super defensiva (SOUZA et al., 2012). As avaliações foram realizadas em 9 repetições, sempre pelo mesmo observador, no período da manhã (entre $8 \mathrm{~h}$ e $11 \mathrm{~h}$ ).

A produção de mel das colônias foi avaliada mediante a pesagem das melgueiras instaladas em cada colmeia no período de alto fluxo nectarífero. A estimativa da produção de mel foi obtida pela diferença entre o peso da melgueira com quadros sem mel (tara) e o peso da mesma melgueira contendo quadros cheios de mel. A pesagem das melgueiras das colônias que tiveram suas rainhas 
substituídas por rainha selecionada só foi realizada após 60 dias da introdução da nova rainha.

As colônias que tiveram suas rainhas substituídas naturalmente permaneceram sendo acompanhadas e quando emergia uma nova rainha, filha da rainha que morreu, a colmeia permanecia com a numeração primária, seguida de uma letra do alfabeto, conforme a sequência de substituição da rainha ocorresse (Ex. C1, C1b, C1c).

Com os dados da $1^{\underline{a}}$ fase experimental foram estabelecidos critérios para atribuição das notas de cada colmeia de acordo com cada característica (Tabela 1).

TABELA 1. Critérios para atribuição da nota de cada colmeia de acordo com as características comportamento higiênica $(\mathrm{CH})$, postura da rainha $(\mathrm{PR})$, produção de mel (PM) e defensividade (DE).

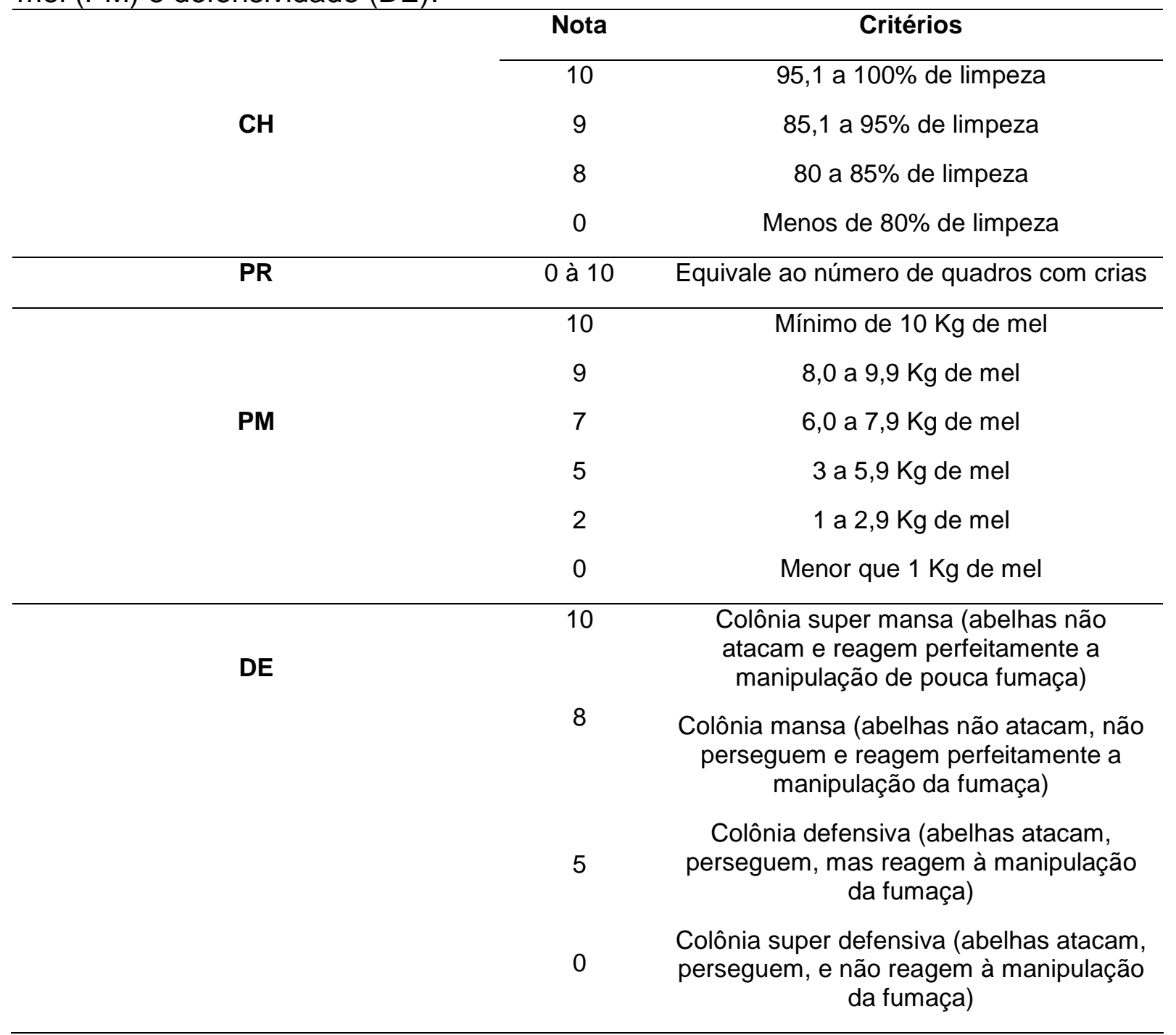

Para o cálculo da média ponderada das colônias $(\mu S)$ para seleção das melhores rainhas como matrizes (CS), convencionou-se que o peso do comportamento higiênico $(\mathrm{CH})$ seria o maior peso (40), por essa característica estar diretamente relacionada com a resistência à doença e sanidade da colônia. As demais variáveis: postura da rainha $(P R)$, produção de mel $(P M)$ e defensividade (DE) peso 20 cada. Fórmula para o cálculo da média de seleção das colmeias: 


$$
\mu S_{C x}=\frac{\sum C H_{x} \cdot 40+P R_{x} \cdot 20+P M_{e \lg x} \cdot 20+D E_{x} \cdot 20}{100}
$$

Onde:

$\mu S_{C x}=$ Média de seleção de cada colmeia, estabelecido pela média ponderada da colmeia $\left(\right.$ colmeia $_{1}$, colmeia $_{2}, \ldots$, colmeia $)$.

$\mathrm{CH}_{x}=$ nota da colmeia $\mathrm{x}$ no teste de comportamento higiênico.

$P R_{x}=$ nota da colmeia referente a postura da rainha.

$P M_{e \lg x}=$ nota da colmeia referente a produção de mel.

$D E_{x}=$ nota da colmeia no teste de defensividade.

Foram selecionadas e classificadas como matrizes "Elite" as colmeias que apresentaram $\mu S$ superior a $80 \%$ ou seja, média ponderada superior a 8,0 . Na $2^{\underline{a}}$ fase experimental foram produzidas rainhas filhas das matrizes selecionadas utilizando o método Doolitle (1899). Colmeias fortes e populosas foram utilizadas como mini-recria modelo Ribeirão Preto (FRANCOY et al., 2005). Foram introduzidas 20 rainhas de $1^{\underline{a}}$, $2^{\underline{a}}$ e $3^{\underline{a}}$ geração nas colônias do apiário experimental AEDZ/UFRPE, que foram fecundadas com zangões disponíveis na natureza e após 60 dias foi realizado a pesagem das melgueiras para mensuração da produção de mel.

Foram também registrados a produção de mel das colônias classificadas como grupo controle, colônias sem estimativa de seleção (SES), colônias matrizes (colônias com $\mu S \geq 8,0$ ) e colônias com rainhas selecionadas de $1^{\underline{a}}$, $2^{\underline{a}}$ e $3^{\text {a }}$ geração (RS1, RS2, RS3). Com a finalidade de comparação foi registrado a produção de mel dos apiários dos apicultores parceiros (AAP).

Todos os dados obtidos sobre as distintas variáveis estudadas foram inicialmente analisados estatisticamente e quantificados com as respectivas médias e desvio padrão (DP). Os dados de produção de mel foram analisados pelo método dos quadrados mínimos segundo o procedimento LSMEANS do SAS. Os dados de contagem foram transformados em logaritmos na base 10 pela fórmula: $\log (x+1)$ e as médias comparadas pelo teste de Tukey a $5 \%$ de significância.

\section{RESULTADOS E DISCUSSÃO}

Com a média dos testes de comportamento higiênico $(\mathrm{CH})$, verificou-se que $67 \%$ das colônias testadas apresentaram alto grau de comportamento higiênico, com média geral do $\mathrm{CH} 93,9 \pm 5,2$, valor máximo de limpeza 100\% e mínimo 85\%; $23 \%$ foram intermediárias com média $67,4 \pm 10,3$ e aproximadamente $10 \%$ não higiênicas com média 34,18ะ16,84 de limpeza.

Quanto ao desempenho de postura da rainha observou-se que as rainhas realizaram postura todos os meses do ano, ocorrendo redução na média do número de quadros com cria apenas nos meses de maio, junho, julho e agosto, que correspondem ao período de chuvas contínuas (Figura 1). 


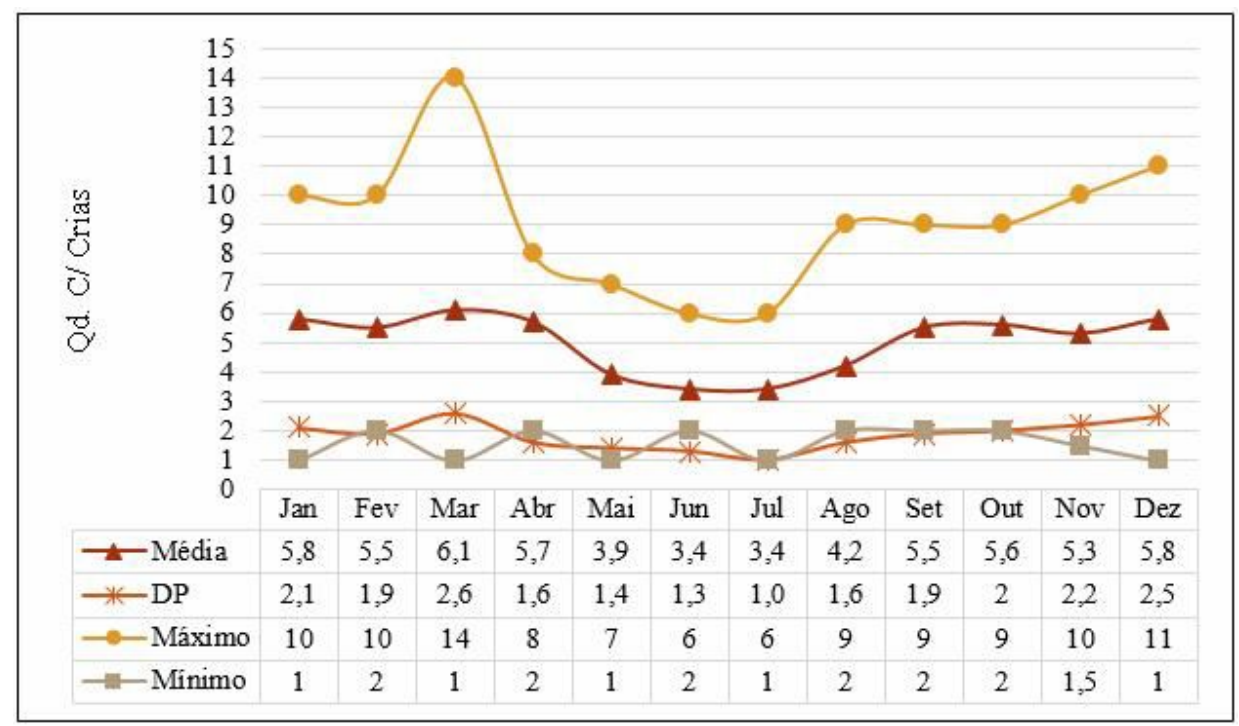

FIGURA 1. Média, desvio padrão (DP), valores máximo e mínimo mensal do número de quadros com crias observadas nas colônias.

No início do experimento em 2014, observou-se no comportamento defensivo das operárias de cada colmeia que, as colmeias C13 e C20 apresentaram comportamento super defensivo; as colmeias C10b, C12b, C18b, C19 e C30 eram defensivas; e a colmeia $\mathrm{C} 12$ super mansa. Após 1 ano de manejo quinzenal, verificou-se que apenas $17 \%$ das colônias ainda apresentavam comportamento defensivo, mas que reagiam bem a manipulação da fumaça tornando possível seu controle. As demais foram classificadas como mansas.

Observou-se que apenas $46,7 \%$ das 30 colmeias estocaram mel nas melgueiras. Resultados semelhantes foram observados nos apiários dos apicultores parceiros, onde $41 \%$ das colônias armazenaram mel em melgueiras, o que demonstra a falta de homogeneidade produtiva das colônias, refletindo uma produção de mel subestimada e uma alta variabilidade genética das colônias avaliadas. Observou-se também, a presença de colônias em que as abelhas operárias puxavam a cera da melgueira, mas não apresentavam aptidão para armazenar mel.

Analisando-se a produção de mel das colônias submetidas ao processo de seleção e com média de seleção igual ou maior a 8,0 (CS), das colônias sem estimativa de média de seleção (SES) e das colônias dos apicultores parceiros (AAP), verificou-se que as colônias CS (média de 12,3 $\pm 6,98$ ) foram 22,8\% superiores às médias das colônias SES (média 9,5 $\pm 3,85$ ) e $46,34 \%$ superiores às médias das colônias AAP (média 6,6 $\pm 5,35$ ) o que demonstra a eficiência do programa de seleção aplicado (Tabela 2 ).

TABELA 2. Produção média de mel em Kg/colmeia das colônias do AEDZ/UFRPE classificadas como $A=$ colônias com média de seleção $C S \geq 8,0 ; B=$ colônias sem estimativa de média de seleção (SES); e $\mathrm{C}=$ colônias dos apiários dos apicultores parceiros (AAP)

\begin{tabular}{c|c|c}
\hline $\mathbf{A}=$ Colônias com $\mathbf{C S} \geq \mathbf{8 0}$ & $\mathbf{B}=$ Colônias SES & $\mathbf{C}=$ Colônias AAP \\
\hline $\mathrm{C} 4 \mathrm{~b}=10 \mathrm{Kg}$ & $\mathrm{C} 2=16 \mathrm{Kg}$ & $\mathrm{AAP} 1=5,8$ \\
\hline
\end{tabular}




\begin{tabular}{c|c|c}
\hline $\mathrm{C} 7 \mathrm{~b}=12 \mathrm{Kg}$ & $\mathrm{C} 6=6 \mathrm{Kg}$ & AAP $2=12,2$ \\
$\mathrm{C} 10 \mathrm{~b}=10 \mathrm{Kg}$ & $\mathrm{C} 8 \mathrm{c}=9 \mathrm{Kg}$ & AAP $3=0,2$ \\
$\mathrm{C} 14 \mathrm{~b}=6 \mathrm{Kg}$ & $\mathrm{C} 11 \mathrm{~b}=14 \mathrm{Kg}$ & AAP $4=8,4$ \\
$\mathrm{C} 28 \mathrm{c}=26 \mathrm{Kg}$ & $\mathrm{C} 13=8 \mathrm{Kg}$ & AAP $5=5,4$ \\
$\mathrm{C} 30 \mathrm{~b}=10 \mathrm{Kg}$ & $\mathrm{C} 18 \mathrm{~b}=11 \mathrm{Kg}$ & AAP $6=0,1$ \\
& $\mathrm{C} 20=6 \mathrm{Kg}$ & AAP $7=13,8$ \\
& $\mathrm{C} 22=6 \mathrm{Kg}$ & \\
\hline Média $\pm \mathrm{DP}=\mathbf{1 2 , 3 \pm 6 , 9 8}$ & Média $\pm \mathbf{D P}=\mathbf{9 , 5} \pm \mathbf{3 , 8 5}$ & Média $\pm \mathbf{D P}=\mathbf{6 , 6} \pm \mathbf{5 , 3 5}$ \\
\hline $\mathrm{A}=\mathbf{2 2 , 8 \%}>\mathrm{B}$ e 46,4\% $>\mathrm{C} ; \mathrm{B}=31 \%>\mathrm{C}$ &
\end{tabular}

Verificou-se que as colônias que apresentaram média de seleção $(\mu S)$ superior a 8,0 foram as colmeias C4b, C7b, C10b, C14b, C28c e C30b, as quais foram classificadas como colônias matrizes elite e apresentaram um alto grau de comportamento higiênico (Tabela 3). As demais colmeias todas tiveram $\mu S$ entre 2,4 e 7,2 .

TABELA 3. Resultado da média de seleção $(\mu S)$ para escolha das colônias matrizes, de acordo com as notas atribuídas às características comportamento higiênicas $(\mathrm{CH})$, postura da rainha (PR), defensividade (DE) e produção de mel (PM).

\begin{tabular}{ccccc|c}
\hline Colmeia & CH & PR & PM & DE & $\mu S$ \\
\hline C3.1a & 10 & 8 & 0 & 8 & 7,2 \\
C4b & 9 & 9 & 10 & 8 & 9 \\
C7b & 10 & 10 & 10 & 8 & 9,6 \\
C10b & 10 & 10 & 10 & 5 & 9 \\
C12b & 10 & 8 & 0 & 5 & 6,6 \\
C13b & 10 & 6 & 0 & 8 & 6,8 \\
C14b & 9 & 10 & 7 & 8 & 8,6 \\
C15c & 10 & 6 & 0 & 8 & 6,8 \\
C16b & 10 & 6 & 0 & 8 & 6,8 \\
C20b & 0 & 8 & 0 & 8 & 3,2 \\
C22b & 9 & 8 & 0 & 8 & 6,8 \\
C25b & 0 & 4 & 0 & 8 & 2,4 \\
C26b & 9 & 6 & 0 & 8 & 6,4 \\
C28c & 10 & 3 & 10 & 8 & 8,2 \\
C30b & 10 & 8 & 10 & 8 & 9,2 \\
\hline
\end{tabular}

Com a obtenção dos índices de seleção foram escolhidas as colônias que apresentaram IS $\geq 8,0$ para serem doadoras de larvas para a produção de rainhas selecionadas. Foram produzidas rainhas de $1^{\text {a }}$ geração filhas das matrizes $\mathrm{C} 7 \mathrm{~b}$, C10b, C14b, C30b e de $2^{a}$ e $3^{\text {a }}$ geração foram produzidas rainhas das matrizes CRS24 e CRS4b respectivamente filhas das rainhas C14b e CRS4. 
$\mathrm{Na}$ produção das rainhas observou-se uma boa aceitação das larvas, chegando a produção de realeiras a um sucesso de $98 \%$ das larvas transferidas, com a taxa de nascimento de $95 \%$, demonstrando que a técnica utilizada para produção de rainhas foi eficiente.

Das rainhas de $1^{\underline{a}}$ geração introduzidas no apiário experimental AEDZ/UFRPE, somente a rainha de uma colmeia permaneceu viva até a época de floração, estocando $13,4 \mathrm{Kg} / \mathrm{mel}$ na melgueira, demonstrando um grande potencial de produção.

Analisando-se a média da produção de mel das colônias com rainhas de $2^{\mathrm{a}} \mathrm{e}$ $3^{\text {a }}$ geração (RS2 e RS3) e das colônias utilizadas como controle no apiário experimental AEDZ/UFRPE, verificou-se que as médias de produção das colônias foram RS2 $=12,9 \pm 3,89 \mathrm{Kg} / \mathrm{mel}$, das colônias RS3 $=13,0 \pm 2,57 \mathrm{Kg} / \mathrm{mel}$ e das colônias Controle $=9,8 \pm 4,87 \mathrm{Kg} / \mathrm{mel}$, apresentando assim as colônias com rainhas de $2^{\underline{a}}$ e $3^{\text {a }}$ geração uma média de produção de mel $24,1 \%$ e $24,6 \%$ respectivamente superiores à média de produção das colônias utilizadas como controle no AEDZ/UFRPE (Tabela 4, Figura 2).

TABELA 4. Produção média de mel em $\mathrm{Kg} /$ colmeia das colônias do AEDZ/UFRPE com rainhas de $2^{\underline{a}}$ (RS2) e $3^{\underline{a}}$ geração (RS3) e colônias utilizadas como colônias controle.

\begin{tabular}{|c|c|c|}
\hline Colônias RS2 & Colônias RS3 & Colônias Controle \\
\hline $\mathrm{CRS} 4 \mathrm{~b}=15,6 \mathrm{Kg}$ & CRS2 $=15,9 \mathrm{Kg}$ & $\mathrm{C} 18=5,5 \mathrm{Kg}$ \\
\hline \multirow[t]{2}{*}{ CRS16 $=10,1 \mathrm{Kg}$} & $\mathrm{CRS} 17=11,1 \mathrm{Kg}$ & $\mathrm{C} 19=8,9 \mathrm{Kg}$ \\
\hline & CRS29 $=11,9 \mathrm{Kg}$ & $\mathrm{C} 20=15,1 \mathrm{Kg}$ \\
\hline Média $\pm \mathrm{DP}=12,9 \pm 3,89$ & Média $\pm \mathrm{DP}=13,0 \pm 2,57$ & Média \pm DP $=9,8 \pm 4,87$ \\
\hline
\end{tabular}

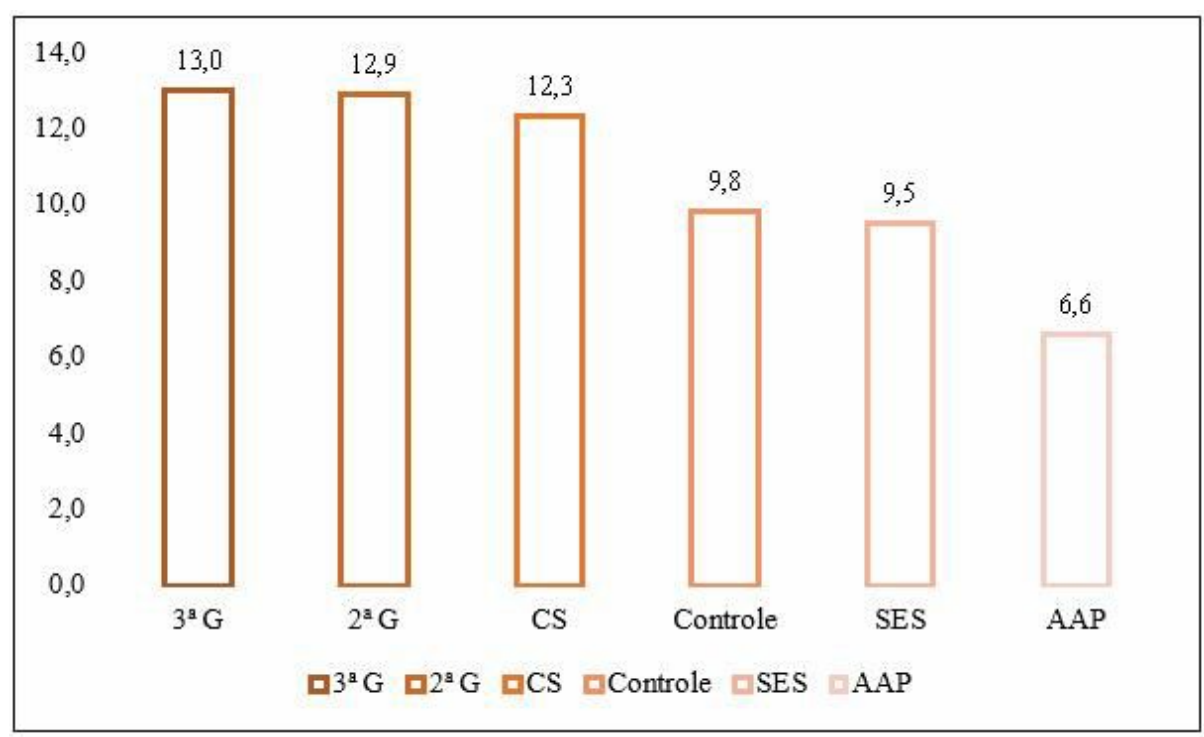

FIGURA 2. Médias da produção de mel (em $\mathrm{Kg}$ ) das colônias com rainhas de $3^{\mathrm{a}}$ e $2^{\mathrm{a}}$ geração (RS3 e RS2), colônias com IS $\geq 8.0$ (CS), colônias controle do apiário experimental, colônias sem estimativa de índice de seleção (SES) e colônias controle dos apicultores parceiros (AAP). 
Comparando pelo método dos mínimos quadrados as médias da produção de mel de todas as colônias analisadas, observou-se que as colônias RS3, RS2 e CS apresentaram diferenças significativas em relação a produção das colônias AAP, mas não diferiram das colônias Controle e SES (Tabela 5).

TABELA 5. Médias, desvio padrão e comparação das médias pelo método dos mínimos quadrados da produção de mel das colônias com rainhas de $3^{\mathrm{a}}$ e $2^{\mathrm{a}}$ geração (RS3 e RS2), colônias com IS $\geq 8.0$ (CS), colônias controle do apiário experimental, colônias sem estimativa de índice de seleção (SES), e colônias controle dos apicultores parceiros (AAP).

\begin{tabular}{ll}
\hline Colônias & Médias e DP \\
\hline $3^{\mathrm{a}} \mathrm{G}$ & $13.0 \pm 2.57 \mathrm{a}^{\star}$ \\
$2^{\mathrm{a}} \mathrm{G}$ & $12.9 \pm 3.89 \mathrm{a}$ \\
$\mathrm{CS}$ & $12.3 \pm 6.98 \mathrm{a}$ \\
Controle & $9.8 \pm 4.87 \mathrm{ac}$ \\
$\mathrm{SES}$ & $9.5 \pm 3.85 \mathrm{ac}$ \\
AAP & $6.6 \pm 5.35 \mathrm{bc}$
\end{tabular}

Médias seguidas de letras iguais na mesma coluna não diferiram entre si pelo Teste de Tukey $(P>0,05)$.

Observou-se que as colônias CS obtiveram um ganho genético de $0,7 \mathrm{Kg}$ na produção de mel, o que equivale a um aumento de $5,4 \%$ na produção. Esses resultados demonstram que é possível criar abelhas mais produtivas mesmo sem o uso de inseminação instrumental das abelhas rainhas.

Comparando-se as médias de produção das colônias RS3 com as colônias AAP, o ganho na produção foi de $6,4 \mathrm{Kg}$ o que representa $49,24 \%$ de aumento na produção de mel (Figura 2). Os resultados obtidos demonstraram eficiência no programa de melhoramento com base em seleção usando-se as variáveis escolhidas (comportamento higiênico, defensividade, postura da rainha e produção de mel) e a forma de cálculo para obtenção da média de seleção utilizada.

A finalidade de um programa de melhoramento genético em abelhas é a obtenção por meio de seleção de linhagens que apresentem as características desejáveis, sendo o comportamento higiênico a característica de maior interesse, por ela estar diretamente relacionada com a sanidade das abelhas, o que interferi diretamente na reprodução, desenvolvimento e produção da colônia. O método de perfuração de células de crias para realização dos testes de comportamento higiênico tem sido estabelecido como uma alternativa barata, prática e rápida a ser utilizada na seleção de colmeias higiênicas (GRAMACHO; GONÇALVES, 1994; PINHEIRO et al., 2015).

A análise conjunta das diferentes características anatômicas, fisiológicas, comportamentais e de desempenhos relacionados à qualidade genética da abelha rainha é descrita em diferentes países do mundo, sendo as condições sanitárias da colônia de importância considerável, por as doenças reduzirem significativamente a longevidade e 0 peso de emergência das abelhas hospedeiro (KHONGPHINITBUNJONG et al., 2016). O que tem levado pesquisadores no Brasil e em alguns países europeus a incluir o comportamento higiênico em seus 
programas de seleção de rainhas com alta qualidade genética (MARTINEZ; SOARES, 2012; HATJINA, 2014). Principalmente nas últimas décadas, que vem ocorrendo um acentuado enfraquecimento e perdas de colônias de abelhas no mundo todo, sendo que no Brasil as mortalidades em massa não estão associadas a parasitas ou patógenos, mas sim a exposição aos agrotóxicos (PIRES et al., 2016).

O grande diferencial das abelhas africanizadas em relação às espécies de abelhas europeias, é que a abelha africanizada apresenta alto nível de comportamento higiênico, eficiência herdada das abelhas africanas, que consiste na extração e eliminação de crias doentes, e o comportamento de grooming que permite eliminar um grande número de parasitas, o que confere a alta tolerância dessas abelhas a doenças, evitando assim a utilização de produtos químicos para controle e/ou tratamento (ALVAREZ; SERRANO, 2011). Como é o caso do controle do parasita ácaro Varroa, que é o principal problema de saúde da apicultura ocidental (FLORES et al., 2015). Sendo que nas abelhas africanizadas, a correlação significativa entre o comportamento higiênico e a taxa de infestação vem proporcionando o controle do Varroa nas colônias de abelhas no Brasil (CASTAGNINO et al., 2016).

Em um programa de melhoramento é necessário considerar a influência dos fatores ambientais na expressão do traço do comportamento higiênico, bem como na morfologia, comportamento e distribuição das abelhas africanizadas, considerando a alta variabilidade genética dentro dessas populações (SOUSA et al., 2016). É importante considerar também, a época ideal de introdução da nova rainha, para que se possa garantir o sucesso na taxa de postura de ovos da rainha e o consequente aumento na produção de mel (CARBONARI et al., 2016).

A defensividade das colônias sofre influências ambientais, não existindo correlação entre produção de mel e defensividade da colônia, o que permite em um programa de melhoramento, selecionar colônias mais produtoras e menos defensivas (SOUZA et al., 2012).

Uma prática de manejo importante que deve ser implementada para que a rainha possa desempenhar todo seu potencial, é o fornecimento de alimento no período de entressafra. A alimentação no período de escassez de alimento na natureza é uma estratégia destinada a aumentar a população de abelhas da colônia, contribuir para evitar as perdas de enxames, o que colaborará para aumento da produtividade (FLORES et al., 2019).

\section{CONCLUSÃO}

Conclui-se que as características comportamentais e produtivas avaliadas e a forma de cálculo para a obtenção da média de seleção foi eficiente para o estabelecimento de um programa de seleção de rainhas matrizes, considerando o comportamento higiênico como a característica mais importante. A capacidade efetiva de sucesso do programa de seleção foi comprovada com o crescente aumento percentual na produção de mel das colônias selecionadas, especialmente em relação as colônias sem estimativa de seleção e dos apiários de produção da região (RS3 = 0,5\% > RS2; 5,4\% > CS; 24,6\% > Controle; $26,9 \%>$ SES; 49,2\% > APP). 


\section{REFERÊNCIAS}

APAC - AGÊNCIA PERNAMBUCANA DE ÁGUAS E CLIMA - Disponível em: < http://www.apac.pe.gov.br/meteorologia/estacoes-do-ano.php?> Acesso em 26 maio 2015.

ALVAREZ, F. P.; SERRANO, J. M. F. Selección de colonias de Apis mellifera iberiensis tolerantes a Varroa destructor. Actas Iberoamericanas de Conservación Animal, v. 1, p. 449-452, 2011. Disponível em: <http://www.uco.es/dptos/zoologia/Apicultura/trabajos_libros/2011_Actas_lberoameri canas.pdf>. Acesso em: 26 jul. 2018.

AMIRI, E.; STRAND, M. K.; RUEPPELL, O.; TARPY, D. R. Queen quality and the impact of honey bee diseases on queen health: Potential for interactions between two major threats to colony health. Insects, v. 8, n. 48, p. 1-18, 2017. Disponível em: <https://www.ncbi.nlm.nih.gov/pmc/articles/PMC5492062/>.doi:10.3390/insects8020 048.

BIGIO, G.; TOUFAILIA, H. A.; HUGHES, W. O. H.; RATNIEKS, F. L. W. The effect of one generation of controlled mating on the expression of hygienic behaviour in honey bees. Journal of Apicultural Research, v.53, n.5, p.563-568, 2014. Disponível em:<https://www.tandfonline.com/doi/abs/10.3896/IBRA.1.53.5.07>. doi: 10.3896/IBRA.1.53.5.07.

CAMARGO, S. C.; LIMA. E. G.; TOLEDO, V. A. A.; GARCIA, R. C. Abelha rainha Apis mellifera e a produtividade da colônia. Scientia Agraria Paranaensis, v. 14, n. 4, p. 213-220, $2015 . \quad$ Disponível em:<erevista.unioeste.br/index.php/scientiaagraria/article/download/13231/9146>. doi: 10.18188/1983-1471/sap.v14n4p213-220.

CARBONARI, V.; ALVES JUNIOR, V. V.; MALASPINA, O; POLATTO, L. P. Variation in honey yield per hive of Africanized bees depending on the introducing time of young queens. Ciência Rural, v.46, n.5, p.895-900, 2016. Disponível em:< http://dx.doi.org/10.1590/01038478cr20151126>. doi:10.1590/01038478cr20151126.

CASTAGNINO, G. L. B.; PINTO, L. F. B.; CARNEIRO, M. R. L. Correlação da infestação de Varroa destructor sobre o comportamento higiênico de abelhas Apis melífera. Arch. Zootec., v.65, n.252, p. 549-554, 2016. Disponível em:< https://www.uco.es/ucopress/az/index.php/az/article/view/1924/1398>. Acesso em: 30 mai. 2019.

DOOLITTLE, G. M. Doolittle's queen rearing methods. American Bee Journal, v. $39, \quad$ n. $28, \quad$ p. $\quad 435-\quad 436, \quad 1899 . \quad$ Disponível em:<https://www.dadant.com/catalog/publications/american-bee-journal>. Acesso em: 30 mai. 2016.

FLORES, J. M.; GIL, S.; PADILLA, F. Reliability of the main field diagnostic methods of Varroa in honey bee colonies. Arch. Zootec., v. 64, n.246, p. 161-166. 2015. Disponível 
$<$ https://pdfs.semanticscholar.org/33db/25bde9bae3f8a2fdd44e2e3e0341c2ee31a0.p df>. Acesso em: 30 mai. 2018.

FRANCOY, T. M.; GONÇALVES, L. S.; SANTOS, J. J.; DE JONG, D. A mini starter finisher hive model that facilitates queen rearing. Apicultural Research, 27 april, 2005. Disponível em:< https://www.academia.edu/14233122/. Acesso em: 30 mai. 2019.

GRAMACHO, K. P.; GONÇALVES, L. S. 1994. Estudo comparativo dos métodos de congelamento e perfuração de crias para avaliação do comportamento higiênico em abelhas africanizadas. In: IV CONGRESSO LATINOIBEROAMERICANO DE APICULTURA. Anais... Argentina, 1994,45 p. Disponível em: <https://www.apacame.org.br/mensagemdoce/52/artigo.htm>. Acesso em: 30 mai. 2019.

GRAMACHO. K. P.; GONÇALVES, L. S. Comparative study of the hygienic behavior of Carniolan and Africanized honey bees directed towards grouped versus isolated dead brood cells. Genetic Molecular Research, v.8, n.2, p.744-50, 2009. Disponível em:<https://www.researchgate.net/publication/26742299>. Acesso em: 30 mai. 2019.

HATJINA, F.; BIEŃKOWSKA, M.; CHARISTOS, L.; CHLEBO, R.; COSTA, C. et al. A review of methods used in some European countries for assessing the quality of honey bee queens through their physical characters and the performance of their colonies. Journal of Apicultural Research, v. 53, n.3, p. 337-363, 2014. Disponível em: < https://www.researchgate.net/publication/263682163>. doi: 10.3896/IBRA.1.53.3.02.

KHONGPHINITBUNJONG, K.; NEUMANN, P.; CHANTAWANNAKUL, P.; WILLIAMS, G. R. The ectoparasitic mite Tropilaelaps mercedesae reduces western honey bee, Apis mellifera, longevity and emergence weight, and promotes Deformed wing virus infections. Journal of Invertebrate Pathology, v. 137, p. 38-42, 2016. Disponível em: <http://dx.doi.org/10.1016/j.jip.2016.04.006>. doi: 10.1016/j.jip.2016.04.006.

MARTINEZ, O. A.; SOARES, A. E. E. Melhoramento genético na apicultura comercial para produção da própolis. Revista Brasileira Saúde Produção Animal, Salvador, v.13, n.4, p.982-990, 2012. Disponível em:< http://www.scielo.br/pdf/rbspa/v13n4/06.pdf>. Acesso em: 30 mai. 2019.

NEWTON D. C.; OSTASIEWSKI N. J. A simplified bioassay for behavioral resistence to American Foulbrood in honey bees (Apis mellifera L.). American Bee Journal, v. 126, p. 278-281, $1986 . \quad$ Disponível em:<https://www.dadant.com/catalog/publications/american-bee-journal>. Acesso em: 30 mai. 2019.

PINHEIRO, M. S. M.; ROYER, A. F. B.; SOUZA, O. M.; SILVA, M. R. Avaliação de dois testes de comportamento higiênico em colônias de Apis melífera. Enciclopédia Biosfera, v.11, n.22, P. 2907-2913, 2015. Disponível em:< doi: http://dx.doi.org/10.18677/Enciclopedia_Biosfera_2015_009. 
PIRES, C. S. S.; PEREIRA, F. M.; LOPES, M. T. R.; NOCELLI, R. C. F.; MALASPINA, O. et al. Enfraquecimento e perda de colônias de abelhas no Brasil: há casos de CCD? Pesq. agropec. bras., v.51, n.5, p.422-442, 2016. Disponível em:< http://www.scielo.br/pdf/pab/v51n5/1678-3921-pab-51-05-00422.pdf>. doi: 10.1590/S0100-204X2016000500003.

SOUSA, A. R. S.; ARAÚJO, E.D.; GRAMACHO K. P.; NUNES, L. A. Bee's morphometrics and behavior in response to seasonal effects from ecoregions. Genet. Mol. Res., v.15, n.2, p. 1-14, 2016. Disponível em: <http://dx.doi.org/10.4238/gmr.15027597> doi: gmr.15027597.

SOUZA, D. A.; GRAMACHO, K. P.; CASTAGNINO, G. L. B. Produtividade de mel e comportamento defensivo como índices de melhoramento genético de abelhas africanizadas (Apis mellifera L.). Rev. Bras. Saúde Prod. Anim., v.13, n.2, p.550557, 2012. Disponível em:< http://www.rbspa.ufba.br> Acesso em: 27 jul. 2018.

SPIVAK, M.; BROWNING, Z.; GOBLIRSCH, M.; LEE, K.; OTTO, C. et al. Why Does Bee Health Matter? The Science Surrounding Honey Bee Health Concerns and What We Can Do About It. CAST Commentary, QTA2017-1, p. 1-16, 2017. Disponível em:<https://conservancy.umn.edu/bitstream/handle/11299/197606/Why\%20Does\%2 0Bee\%20Health\%20Matter.pdf?sequence=1>. Acesso em: 31 mai. 2019.

TARPY, D. R.; KELLER, J. J.; CAREN, J. R.; DELANEY, D. A. Experimentally induced variation in the physical reproductive potential and mating success in honey bee queens. Insect. Soc., v. 58, p. 569- 2011. Disponível em:< https://link.springer.com/article/10.1007\%2Fs13592-018-0614-y>. doi: 10.1007/s00040-011-0180-z.

WAGONER, K. M.; SPIVAK, M.; RUEPPELL, O. Brood Affects Hygienic Behavior in the Honey Bee (Hymenoptera: Apidae). Journal Econ Entomol., v.111, n.6, p.25202530, 2018. Disponível em:<https://www.ncbi.nlm.nih.gov/pubmed/30212863>. doi: 10.1093/jee/toy266. 